\title{
Research on Talent Incentive Mechanism in the Closed Type Healthcare Alliance
}

\author{
Jing Zhang1, Mingmin Wang2², Yahui Ma1, Yaoyao Jia ${ }^{3}$, Guangpeng Zhang ${ }^{3}$ \\ ${ }^{1}$ Qingdao University, Qingdao, China \\ ${ }^{2}$ The Sixth People's Hospital of Qingdao, Qingdao, China \\ ${ }^{3}$ China National Health Development Center, Beijing, China \\ Email: *wangmm1963@sina.com
}

How to cite this paper: Zhang, J., Wang, M.M., Ma, Y.H., Jia, Y.Y. and Zhang, G.P. (2017) Research on Talent Incentive Mechanism in the Closed Type Healthcare Alliance. Open Access Library Journal, 4: e4018.

https://doi.org/10.4236/oalib.1104018

Received: October 10, 2017

Accepted: November 27, 2017

Published: November 30, 2017

Copyright $\odot 2017$ by authors and Open Access Library Inc.

This work is licensed under the Creative Commons Attribution International License (CC BY 4.0).

http://creativecommons.org/licenses/by/4.0/

\begin{abstract}
The construction and development of the closed type health care is an important measure to deepen the reform of the three medical entities, to rationally allocate medical and health resources, to enable the grassroots people to enjoy the high quality and convenient medical services, and for the efficient implementation of closed type medical alliance, the perfect incentive mechanism plays a particularly important role. Through combing the current situation of talent incentive mechanism in closed type health care alliance of China, this paper discusses the challenges in practice and puts forward some feasible suggestions in order to promote the further development of close type medical alliance.
\end{abstract}

\section{Subject Areas}

Health Policy

\section{Keywords}

The Closed Type Health Care Alliance, Talent, Incentive

\section{Introduction}

In recent years, both the central and local governments are actively exploring how to improve the health care services of primary-level medical and health care institutions, to restore the functions of primary health care institutions, to implement the hierarchical treatment policy, and to achieve high-quality medical resources sinking. It has proved to be effective and feasible that the closed type health care alliance is able to strengthen the link between urban and rural areas and promote the common development of urban and rural areas. 
The closed type health care alliance refers to a certain area; the superior hospital held directly or through the purchase and merger of junior hospital formed a cooperative asset, so that medical and health resources of health manpower, technology, capital, information and other resources can be unified deployment and overall management. The closed type health care alliance of all medical and health institutions as a whole, involving property rights reform and reorganization, touches the larger interests, the unit of original management rights and capital property transferred to the unified consortium, and makes resource allocation efficiency higher, which belongs to the common interests of the real, such as the straight tube medical syndicate of NO.5 People's Hospital of Wuhan, Luohu District Medical Group, Urban-Rural Integration in Qidong City, County Medical Community in Tianchang City, Anhui Province, and Urban-Rural Health Institutions in Fangzi District of Weifang. Talent incentive incentives are an important part of achieving the closed type health care alliance. Because the closed type health care alliance is cross-team, cross-agency and even cross-regional, there is a need to establish a corresponding incentive mechanism for talent. This paper summarizes the current situation of talent incentive mechanism in China's close type health care alliance, discusses the challenges in practice and puts forward some feasible suggestions to promote the reform of the closed type health care alliance.

\section{Materials and Methods}

\subsection{Collect Information}

First, literature induction. We use "medical association", "closed type health care alliance", "health integration" and "talent motivation" to search the literature search terms and summarized the information on the incentive mechanism of closed type health care alliance; second, summarize the policy. We have combed our country's relevant policy documents for the last 10 years to clarify the national policy guidance and requirements; third, network retrieval, summarized the practice of incentive mechanism of the closed type health care alliance in China for nearly 10 years.

\subsection{Stakeholder Interviews}

We conducted a field survey of talent incentives in Jimo medical services county integration and Urban-rural Health Institutions in Gaoxin District of Weifang, interviewed with 15 related management personnel and 33 medical staff, to understand their views and suggestions on the incentive mechanism of the closed type health care alliance.

\section{Status Quo of Talent Incentive Mechanism of the Closed Type Health Care Alliance}

The perfect talent incentive mechanism is particularly important for the effective promotion of the closed type health care alliance, in the practice around the tal- 
ent incentive practice is mainly reflected in the following five aspects.

\subsection{Wage Income}

In the model of the closed type health care alliance, the exploration of wage income mainly revolves around the two aspects of performance pay and helping subsidy, subsidies are generally issued to Finance Assistance subsidy form to the Commonwealth, to support the personnel service subsidies, to encourage staff, helping grassroots grass roots sinking. Support staff salaries and benefits are paid by the original unit, and according to the business assessment and performance appraisal method of the recipient unit. Such as the NO.5 people's hospital of Wuhan straight tube medical syndicate [1] [2], supporting staff can get a subsidy of $\$ 2000 /$ month, in addition, the basic salary of the community director issued by the NO.5 people's hospital, performance pay is based on community performance, the annual income is based on the same medical staff's standard in the NO.5 people's hospital. The core hospital group in Zhenjiang medical group each has a doctor sit in community, they can get 80 thousand yuan of financial subsidies. The urban-rural integration in Qidong City [3] has tried the annual salary system of the president of the group and the annual salary of all the member units, which are separately allocated by the municipal financial allocation and the overall expenditure of the basic level hospitals, and are not included in the total amount of the hospital wages. Xi'an implements medical services county integration [4], which provides more performance subsidies for medical staff working in township health centers. Shunyi District, Chinese medicine and medical complex in two institutions (central area and cattle bar mountain branch area) workers equal pay for equal work, enjoy the same performance wage.

\subsection{Performance Appraisal}

In the closed type health care alliance, the performance goals and assessment indexes of hospital medical personnel at all levels are generally formulated by the core hospitals, and the allocation incentive mechanism of salary distribution according to performance is established at each level. However, different forms of medical consortium have different sources of assessment. Such as the Integration Management of Urban-rural Health Institutions in Fangzi District of Weifang [5], community (township) assessment standards unified by the district hospital to develop, and the district hospital departments to conduct business assessment.

\subsection{Expand the Career Development Space}

The core of hospital sent support personnel, one will support the staff of the title promotion, advanced selection and so on with the grassroots practice services linked; the second is through the placement of the way to solve the job promotion path. For the primary health care personnel, through the training in the higher level of the hospital or with the higher level of hospital experts work, to promote and enhance personal ability and technical level. 


\subsection{Benefits}

Some members organizations provide accommodation, meals, shuttle and other benefits to support personnel, so as to facilitate their services to the primary health care institutions.

\subsection{Recognition Award}

Some areas also give support staff honorary title or recognition. In 2013, the Gansu Provincial Health Family Planning Commission set a total of 19 awards, of which there are three for the grassroots talent, such as "rooted in rural areas for three decades", and so on.

\section{Challenges to the Talent Incentive Mechanism of the Closed Type Health Care Alliance}

\subsection{It Is Difficult to Break through the Total Performance of the Total Wage, Medical Union Distribution Autonomy Is Limited}

The performance salary system is implemented in health institutions in China, and performance pay is a variable part of staff salaries. No one can break the approved total performance salary, performance salary total authorized medical institutions of different levels, different nature, cannot be paid any allowance or bonuses in the amount of post performance salary. Most of our primary health care institutions in the implementation of the "two lines of revenue and expenditure" management, that is, all income turned over to the local finance, all the expenditure by the financial expenditure allocated by the approved expenditure, expenditure and income decoupling, and the total expenditure of staff and the amount of staff strictly linked. Performance of the total wage control is the contradictory point of implementing in the closed type health care alliance. Health care institutions at all levels in the performance of wages and subsidies to pay the issuance of almost no autonomy, which makes the urban and rural medical personnel between the technical labor value is difficult to reflect, but also makes the various levels of institutions and medical staff participation and enthusiasm is poor.

\subsection{Support Subsidies to Subsidize the Standard, the Intensity and the Source Difference Is Relatively Large}

The root cause of rising wages is the increase in the fixed portion of the total wage, rather than the increase in performance-based incentives. As the primary health care unit is the implementation of the "revenue and expenditure two lines" management, which makes support to support the performance of experts wages, subsidies cannot be guaranteed subsidies. In addition, we need to pay attention to is that, in order to meet the development needs, many medical and health institutions employ a large number of temporary staff, and the preparation of external staff does not belong to the performance of the implementation of the object, not in the financial subsidies, making the same job obvious. Al- 
though some institutions to help experts to provide help subsidies, but there are different subsidies, the intensity is not the source of different sources.

\subsection{Performance Assessment Methods in Name Only, the Application of Assessment Standards, Targeted Is Not Strong}

The hospital in accordance with the employment contract for medical staff to carry out the usual assessment, the annual assessment and employment assessment, the assessment of the main body is the hospital, the assessment criteria are different in each hospital, the assessment results as a adjustment of medical staff positions, wages and renewal of the contract in accordance with. In the closed type health care alliance, contents and subjects of the staff and the main body will also have new changes and become new problems. The survey found that some of the medical partners to develop staff performance appraisal methods in name only, did not play a practical effect, and the application of the assessment criteria, targeted is not strong.

\subsection{Institutional and Medical Staff Involved in the Poor Enthusiasm}

At present, the effective combination of health insurance system and two-way referral system is relatively low, and different medical security systems are implemented in urban and rural areas. The two systems are different in terms of payment method, financial subsidy level and fund raising level. The synergy is weak. Although a small number of places explore the total amount of medical insurance prepaid system, the balance of medical insurance funds redistribution, but the balance of funds allocated by the institutions can be used for staff incentives, there is no standard. In addition, the government funding for institutions, hospitals are inadequate, not timely, not in place, and help the grassroots with gratuitous, making a lot of core hospitals bear the cost of lack of motivation to help. The core hospital staff medical research teaching and personal titles linked to pay, and to prevent health care, common diseases mainly grassroots health work on medical personnel to enhance technology and scientific research and teaching work is not helpful, so that doctors sent to the grassroots lack of enthusiasm or Lack of work, only as a directive task. In addition, the core hospital medical staff to accept the hospital tasks to their partners to provide support services on a regular basis, to a certain extent, the impact of its work in the original unit, but also may therefore be missed to the higher level hospital study or study abroad study and influence its own career development.

\section{Promote the Construction of the Talent Incentive Mechanism of the Closed Type Health Care Alliance}

\subsection{Play the Role of Government, Adjust the Distribution of Benefits Mechanism}

The government is an important force in advancing the closed type health care 
alliance, requiring better policy-oriented roles, optimizing top-level design, and providing different measures and policy support depending on the needs, such as financial subsidies. To promote the payment reform of the closed type health care alliance, playing the role of health care leverage is an opportunity to promote the interests of institutional adjustment. First, the role of health care incentives should be played fully to promote the medical union to carry out health insurance payment reform, that is, the total amount of medical insurance prepaid system is to improve the enthusiasm of the agencies to participate in and encourage the allocation of surplus funds to extract a certain proportion of staff incentives. Second, we should increase government investment, eliminate division of the sector, and open up sources of funding channels.

\subsection{Break through the "Income and Expenditure Two Lines", Giving the Distribution of Autonomy to the Closed Type Health Care Alliance}

The breakthrough performance of the total wages is limited; the total amount of performance pays to health care alliance, giving institutions or health care alliance to allocate autonomy. It allows breaking through the salary regulation level of the current public institutions, and allows the medical service income to deduct the cost and extract the funds according to the regulations, and mainly used for the personnel reward. A special fund for performance appraisal is set up, whose expenditure is charged by the financial departments at different levels, not included in the total performance of wages. At the same time, we explore the implementation of equal pay for equal work within the compact medical association.

\subsection{Principle of "More Pay for More Work, Excellent Work for Excellent Reward" and Implementation of Performance Appraisal Results Linked to the Performance of the Wage System}

To formulate an integrated performance appraisal and subsidy scheme allocation method (main body, content, standard, scope, etc.), and in strict accordance with the results of the assessment of performance distribution, we will participate in grass-roots help into the personal performance of doctors. Or the performance appraisal method should be set up according to the business center, that is, the center as the basic unit of performance appraisal and salary payment. The medical staff income is no longer directly linked with the economic benefits of the unit, but by its unit based on the results of performance appraisal release.

\subsection{Broaden the Professional Development of Medical Staff Space}

Continuing to implement the medical staff promotion mechanism linked to the primary health care service time, medical personnel must advance to the primary health care service for a period of time, and reach a certain quality of service. At the same time, weakening the role of scientific research and teaching in the 
period of help, will help as a favorable condition into the individual annual assessment range. In addition, the higher level of learning opportunities broadens the career development space, and improves the effectiveness of incentives.

\section{Funding}

China-WHO 2016-2017 Biennial Cooperation Project (WHO Reference 2016/ 648677-0 Purchase Order 201554266).

\section{References}

[1] Huang, P. and Yi, L.H. (2015) Practice and Consideration on Three Types of Medical Alliance Modes. Chinese Hospital Management, 35, 16-19.

[2] Liang, S.Y., He, L., Song, S.H., Jin, Y.Z., Yuan, B.B. and Meng, Q.Y. (2016) China's Medical Development and Practice of Typical Analysis. China Health Policy Research, 9, 42-48.

[3] Shen, J.T. (2016) Practice and Exploration of Establishing the Medical Management Group and Implementing Urban-Rural Integration in Qidong City, Jiangsu Province. Chinese Journal of Medical Management Sciences, 6, 18-22.

[4] Liu, S.Z. (2014) Practice on County and Township Health Service Integrated Delivery Mode in Xi'an. Chinese Hospitals, 18, 1-3.

[5] Wu, Z.G., Yang, W.X., Wang, X.X., Shan, J., Mu, Q.P., Zhang, W.J., et al. (2011) Practical Exploration on the Integration Management of Urban-Rural Health Institutions in Fangzi District of Weifang. Chinese Primary Health Care, 2011, 16-17.

Submit or recommend next manuscript to OALib Journal and we will provide best service for you:

- Publication frequency: Monthly

- 9 subject areas of science, technology and medicine

- Fair and rigorous peer-review system

- Fast publication process

- Article promotion in various social networking sites (LinkedIn, Facebook, Twitter, etc.)

- Maximum dissemination of your research work

Submit Your Paper Online: Click Here to Submit

Or Contact service@oalib.com 